\title{
A problemática ambiental dos poluentes emergentes: possíveis impactos por hormônios sexuais
}

O aumento da contaminação dos recursos hídricos tem preocupado a comunidade científica, em relação a qualidade das águas, tendo em vista que é um dos elementos primordiais a continuação da vida no planeta. A fragilidade dos sistemas de saneamento, aliadas ao crescimento populacional, tem auxiliado para que esgoto domésticos e efluentes industriais sejam lançados em águas superficiais. Uma classe de poluentes tem chamado a atenção de várias autoridades e pesquisadores: Contaminantes Emergentes (CE) ou Poluentes Emergentes (PE), são substâncias encontradas em concentrações muito baixas em ordem de nanogramas ou picogramas. A partir de um desenho metodológico dessa problemática, utilizou-se o método dedutivo e abordagem qualitativa, bem como técnica de pesquisa bibliográfica, onde pode-se constatar que dentre os contaminantes os Interferentes Endócrinos (IE), tem-se destacado, devido seu potencial em causar danos à saúde humana e de outras espécies animais, o que levou a Agência de Proteção Ambiental dos Estados Unidos (USEPA) a definir como umas das 6 áreas de pesquisas mais importantes. Os hormônios sexuais femininos (HSF) estão dentre os interferentes endócrinos que merecem uma devida atenção. Os hormônios femininos ou estrógenos podem ser naturais (produzidas pelo organismo animal) tais como: 17ß-estradiol, estriol, estrona ou sintéticas (17a-etinilestradiol) produzidos para fins de reposição hormonal ou como métodos contraceptivos. Dessa forma, este trabalho tem como objetivo esclarecer a comunidade acadêmica e sociedade em geral sobre a problemática em torno dos Poluentes Emergentes, em especial, os hormônios sexuais.

Palavras-chave: Contaminantes Emergentes; Interferentes Endócrinos; Toxicologia ambiental.

\section{The environmental problem of emerging pollutants: possible impacts by sex hormones}

\begin{abstract}
The increasing contamination of water resources has been worrying the scientific community regarding water quality, considering that it is one of the primary elements the continuation of life on the planet. The fragility of sanitation systems, coupled with population growth, has helped domestic sewage and industrial effluents to be discharged into surface waters. A class of pollutants has caught the attention of several authorities and researchers: Emerging Contaminants (EC) or Emerging Pollutants (PE) are substances found in very low concentrations in order of nanograms or picograms. From a methodological design of this problem, we used the deductive method and qualitative approach, as well as bibliographic research technique, where it can be seen that among the contaminants Endocrine Interferents (IE), has been highlighted due to its potential causing harm to human health and other animal species, which led the US Environmental Protection Agency (USEPA) to define as one of the 6 most important areas of research. Female sex hormones (HSF) are among the endocrine disruptors that deserve due attention. Female hormones or estrogens may be natural (produced by the animal organism) such as: 17ß-estradiol, estriol, estrone or synthetic (17a-ethiny estradiol) produced for hormone replacement purposes or as contraceptive methods. Thus, this work aims to enlighten the academic community and society in general about the issues surrounding Emerging Pollutants, especially sex hormones.
\end{abstract}

Keywords: Socioenvironmental impacts; Hydroenergy; Negative externalities.

Topic: Desenvolvimento, Sustentabilidade e Meio Ambiente

Reviewed anonymously in the process of blind peer

Jerri Adriano Vieira Lima

Universidade Federal de Rondônia, Brasil http://lattes.cnpq.br/3607713824499216 http://orcid.org/0000-0002-9959-1618

jerri_a@hotmail.com

Rosalvo Stachiw (id

Universidade Federal de Rondônia, Brasil http://lattes.cnpq.br/1646641940410936 http://orcid.org/0000-0001-6901-3852 rosalvo stachiw@unir.br

Julio Sancho Linhares Teixeira Militão Universidade Federal de Rondônia, Brasil http://lattes.cnpq.br/1678856829160058 militao@unir.br

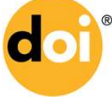

DOI: 10.6008/CBPC2318-2881.2019.001.0007
Received: $17 / 01 / 2019$

Approved: 23/04/2019
Referencing this:

LIMA, J. A. V.; STACHIW, R.; MILITÃO, J. S. L. T.. A problemática ambiental dos poluentes emergentes: possíveis impactos por hormônios sexuais. Nature and Conservation, v.12, n.1, p.66-74, 2019. DOI: http://doi.org/10.6008/CBPC2318-2881.2019.001.0007 


\section{INTRODUÇÃO}

A fragilidade dos serviços de saneamento e das políticas públicas, somadas ao crescimento populacional desorganizado, são considerados como fatores intrínsecos para a diminuição da qualidade dos nossos recursos hídricos e da integridade dos solos. A inexistência de um planejamento baseado em critérios ambientais e toxicológicos, permite que ainda exista o lançamento de cargas industriais e esgotos domésticos nos sistemas de águas superficiais (TARTARI, 2005).

A ineficiência de um sistema de coleta aliado ao crescente uso de compostos químicos, bem como o lançamento inadequado destes efluentes industriais e domésticos têm levado ao surgimento dos chamados contaminantes emergentes (CE) ou poluentes emergentes (PE) nos ecossistemas aquáticos e terrestres. Os PE são micropoluentes, detectados em concentrações muito baixas, na ordem de microgramas ou nanogramas em diferentes matrizes biológicas. Podendo ser de ocorrência natural ou de origem antropogênica. A grande preocupação é com os possíveis efeitos deletérios ao ecossistema terrestre, aquático e até mesmo na saúde humana em decorrência da inclusão desses poluentes nos diferentes compartimentos ambientais, uma vez que estes não são legislados pelos serviços de monitoramento ambiental (PETROVIC et al., 2006).

Os poluentes em questão podem atuar como Interferentes Endócrinos (IE), ou seja, essas substâncias podem alterar, de alguma forma a produção, liberação e atividade de hormônios no organismo, podendo acarretar em diversos problemas a saúde animal, tais como câncer de mama ou de testículo no homem e em alguns estudos também se mostrou a capacidade desses poluentes de causarem alterações na reprodução de aves e peixes.

O departamento de pesquisa e desenvolvimento da Agência de Proteção Ambiental dos Estados Unidos (USEPA), desde 1996, vem dando ênfase nos estudos em relação a estas substâncias, pois considera a identificação e quantificação de interferentes endócrinos como uma das seis áreas de pesquisas mais importantes, atribuído ao aumento expressivo desses compostos ao longo dos últimos anos. Os hormônios sexuais femininos (HSF) estão dentre os interferentes endócrinos que merecem uma devida atenção, já que a demanda por anticoncepcionais aumentou consideravelmente, tendo como fator preponderante a inserção da mulher no mercado de trabalho e consequentemente o controle da sua fertilidade (USEPA, 1997).

Cabe, no entanto, salientar que hormônios estrogênios ou hormônios ditos sexuais, são substâncias biologicamente ativas derivadas de ésteres de colesterol podendo ser de origem natural, tais como aqueles produzidos e liberados por glândulas como pelo córtex adrenal, testículos, ovários e placenta de humanos e outras espécies animais, bem como de produtos sintéticos produzidos com fins terapêuticos na saúde humana e ou animal (HAMID et al., 2012; YING et al., 2002).

Ainda que os impactos ao ecossistema e a saúde das espécies sejam poucos quantificáveis pela carência de pesquisas contundentes a esse respeito, a problemática dos poluentes e em especial dos hormônios sexuais que será abordado neste estudo, não pode ser olvidado. Objetiva-se assim, através dessa revisão, esclarecer a comunidade acadêmica e a sociedade em geral, a problemática em torno dos poluentes 
emergentes e os possíveis efeitos deletérios que estes possam representar ao ecossistema de maneira geral e a saúde humana e de outras espécies animais.

\section{MATERIAIS E MÉTODOS}

A metodologia adotada nesse trabalho é a pesquisa descritiva, que segundo Cervo (2006), trata-se de uma observação, registro, análise e correlação de fatos ou fenômenos sem manipulá-los. A abordagem utilizada foi qualitativa, e o método dedutivo, uma vez que a partir da análise conceitual de poluentes emergentes e hormônios estrogênios (sexuais) e dos seus possíveis impactos socioambientais em caráter geral, passou-se ao estudo da realidade em vários locais onde trabalhos relatam essa problemática. 0 procedimento de pesquisa utilizado foi bibliográfico e documental, pois utilizou-se de fontes primárias e secundárias que tratam da temática, tais como livros, artigos, dissertações de mestrado, teses de doutorado, e de revistas científicas publicadas de domínio público (MANZINI, 2006).

\section{DISCUSSÃO TEÓRICA}

\section{Poluentes Emergentes como interferentes endócrinos (IE)}

No início do século XX, começou-se a estudar os micropoluentes com capacidade de interferir no sistema endócrino de seres humanos e de outras espécies animais, sendo por assim chamados inicialmente de Interferentes Endócrinos (IE). Essas substâncias de origem natural ou sintéticas têm chamado a atenção da comunidade científica devido o potencial tóxico aos seres que estão em constante exposição, já que sua utilização se faz em diferentes grupos de produtos, tais como: fármacos, produtos de higiene, sanitários, entre outros. Ou mesmo aqueles naturais que são excretados pelo organismo de espécies vertebradas ou invertebradas (BLEDZKA et al., 2010).

Ainda segundo Bledzka et al. (2010), os IE mesmo em pequenas concentrações, como na ordem de nanogramas, são capazes de causar efeitos adversos nos organismos vivos. Tais contaminantes são definidos pela Agência de Proteção Ambiental dos Estados Unidos (USEPA) como substâncias exógenas capazes de interferir na produção, secreção, transporte, ligação, ação ou eliminação dos mensageiros químicos naturais responsáveis pela manutenção do equilíbrio (homeostase) fisiológico, desenvolvimento, reprodução e comportamento das espécies.

Os hormônios são liberados em concentrações específicas, para que atue de forma seletiva em seus receptores. No entanto, outras substâncias orgânicas, exógenas podem acabar se ligando aos receptores endógenos, dependendo das suas características físico-químicas, afinidade por receptor, estrutura molecular semelhantes a substâncias endógenas, e concentração das mesmas no protoplasma biológico, é justamente nesse momento que os possíveis efeitos dos IE podem surgir (SODRÉ et al., 2007).

Para Ghiselli et al. (2007), os interferentes endócrinos podem afetar a atividade do sistema endócrino de três maneiras: imitando a atividade de determinado hormônio natural, como o estrogênio e a testosterona, promovendo uma cascata de reações químicas semelhantes no organismo. Se ligando aos 
receptores nas células que recebem os hormônios, bloqueando a ligação destes e/ou alterando a síntese, transporte, metabolismo e excreção dos hormônios, alterando assim os níveis de concentrações dos hormônios naturais. No entanto ação dos IE ainda, não são de todo esclarecido, necessitando de maiores pesquisas para que se possa elucidar todos os efeitos e riscos destes nos compartimentos biológicos. A tabela I consta algumas substâncias esteroides listadas pelas organizações mundiais cientificas como IE.

Tabela 1: Substâncias esteroides e sua ocorrência.

\begin{tabular}{|l|l|}
\hline Substâncias & Onde são encontradas/Finalidade \\
\hline Esteroides & $\begin{array}{l}\text { Grupo de compostos lipossolúveis, naturais (produzidas pelo organismo humano e outras espécies animais) ou } \\
\text { sintéticos (produzidos artificialmente por indústrias farmacêuticas, com finalidade médico-terapêutica). }\end{array}$ \\
\hline Etinilestradiol & $\begin{array}{l}\text { Principal estrogénio endógeno nos seres humanos. É um estrogênio bioativo utilizado em muitas formulações } \\
\text { de pílulas anticoncepcionais orais combinados. }\end{array}$ \\
\hline $\mathbf{1 7 \beta}$ - Estradiol & $\begin{array}{l}\text { Hormônio sexual e esteroide, o principal hormônio sexual feminino. É importante na regulação do ciclo estral } \\
\text { em animais e do ciclo menstrual nas mulheres. }\end{array}$ \\
\hline Estrona & $\begin{array}{l}\text { A estrona é um hormônio estrogênico secretado pelo ovário. É produzida a partir da androstenediona. A estrona } \\
\text { é o segundo estrogênio predominante na circulação na mulher e predominante após a menopausa. }\end{array}$ \\
\hline Mestranol & $\begin{array}{l}\text { Pode ser chamado de etinilestradiol 3-metil éter, é um estrogênio esteroide sintético que tem sido largamente } \\
\text { empregado para fins contraceptivos. }\end{array}$ \\
\hline Dietilestilbetrol & $\begin{array}{l}\text { Estrogênio não esteroide sintetizado pela primeira vez em 1938. Administrado como fármaco para o tratamento } \\
\text { médico para determinadas doenças, incluindo cancro da mama e cancro da próstata. }\end{array}$ \\
\hline
\end{tabular}

Fonte: Ghiselli et al. (2007).

Devido a periculosidade e da persistência desses poluentes em diferentes matrizes aquáticas, abordadas em outros trabalhos, dar-se ênfase nos IE em especifico estes já supracitados (hormônios sexuais), uma vez que além de serem excretados por organismos vivos, estão presentes nos medicamentos anticoncepcionais, ou medicamentos com fins terapêuticos de reposição hormonal.

\section{Características gerais dos hormônios}

As funções corporais, incluindo o metabolismo, crescimento e desenvolvimento, balanço hidroeletrolítico, reprodução e comportamento, são controladas por um complexo sistema endócrino, constituído por glândulas que secretam substâncias que irão desempenhar variadas funções em tecidos alvos. A homeostase fisiológica só é possível graças aos chamados hormônios ou mensageiros químicos, substâncias essas que podem ter diferentes características físico-químicas, meios de transporte, ligação e ação no organismo (GUYTON, 2011)

Ainda de Acordo com Guyton (2011), existem três classes gerais de hormônios, a saber: Proteínas e polipeptídios: são hormônios secretados pela hipófise, pelo pâncreas, pela paratireoide, entre outros; Esteroides: são aqueles secretados pelo córtex adrenal, pelos ovários, testículos e pela placenta; e Derivados do aminoácido tirosina: são secretados pela tireoide e medula adrenal.

A figura 1 ilustra as nove glândulas que compõe o sistema endócrino; o hipotálamo é responsável por controlar a produção de mensageiros químicos pelas outras glândulas; a glândula pituitária libera e controla a liberação de outros tecidos endócrinos; a tireoide produz os hormônios que controla o metabolismo basal celular; as paratireoides regula o metabolismo do cálcio entre os fluidos e os ossos; o pâncreas controla os níveis de glicemia com a liberação de insulina e glucagon, o testículo no homem e os 
ovários na mulher, estão responsáveis pela produção de hormônios androgênicos, e estrogênicos respectivamente; que fazem o controle das características sexuais secundarias em ambos os sexos.

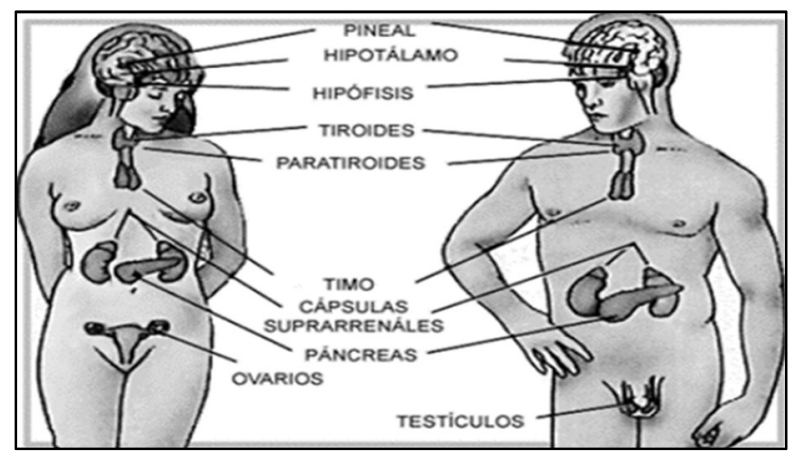

Figura 1: Locais anatômicos das principais glândulas endócrinas e tecidos do corpo.

A maioria dos hormônios esteroidais, secretados pelas gônadas masculina e feminina, são em sua maior parte derivados de ésteres de colesterol ou possuem estrutura semelhante a estes, o que pode estar relacionado a sua capacidade de bioacumulação quando em grandes concentrações. Os hormônios femininos produzidos pelos ovários são basicamente estrogênio e progesterona, no entanto, temos as variações, que advém da formação destes, tais como o estradiol, estriol e estrona. Os hormônios femininos citados podem ser considerados naturais por serem produzidos pelo organismo, no entanto, podemos encontrar estrogênios sintéticos que são aqueles empregados em formulações farmacêuticas, obtidas através de alterações moleculares nos hormônios esteroides.

O emprego desses produtos sintéticos é como contraceptivos, como repositor hormonal e/ou tratamento de algumas neoplasias especificas (RAIMUNDO, 2011). Ainda segundo Raimundo (2011), a disseminação dos contraceptivos, fez com que a taxa que era de 6,2 nascidos por mulher no ano de 1950 e, de 5,8 em 1970, diminuiu para 4,2 em 1980 quando os contraceptivos começaram a se consolidar, em 2010 a taxa diminuiu para 1,86 filho por mulher. Isso mostra que o consumo dos contraceptivos se tornou crescente e cada vez mais necessário numa sociedade moderna, onde as mulheres ascendem profissionalmente e assumem outro papel, que não aquele de dona de casa e sim de mulheres que decidem sobre quando e como ter filhos.

O destino desses produtos à base de hormônios estrogênicos é que preocupa a comunidade cientifica, seja pelo descarte inapropriado dos compridos que sobram, vencem, ou são trocados por outros, bem como os resíduos do processo de metabolização do organismo humano. Pois toda substância ingerida ou mesmo as de origem natural serão excretadas nas fezes ou urinas de forma conjugada ou inalterada. Posteriormente essas substâncias vão pouco a pouco se tornando parte das diferentes matrizes biológicas, levantando questões de saúde ambiental e coletiva.

\section{Aporte e interação com o meio ambiente}

A quantidade de hormônios esteroides excretados por humanos e outras espécies animais, variam muito em decorrência do estado nutricional, idade, gravidez, lactação e saúde dessas espécies. Através da 
descarga de águas residuais, dejetos, e principalmente através de despejo inadequado nos efluentes, tem contaminado o meio ambiente e consequentemente as águas superficiais. A incorporação desses hormônios nas matrizes biológicas depende das características físico-químicas dos mesmos, polaridade, afinidade a água e os meios pelos quais são introduzidos nos meios aquáticos (CAMPBELL et al., 2006). A tabela 2 mostra a quantidade média dos valores de estrógenos excretados diariamente na diurese de humanos.

Tabela 2: Média dos valores de estrógenos excretados diariamente na diurese de humanos.

\begin{tabular}{|l|c|c|c|c|}
\hline \multicolumn{1}{|c|}{ Estrógeno } & Excreção masculina $(\boldsymbol{\mu g} / \mathbf{2 4 h})$ & $\begin{array}{c}\text { Excreção feminina } \\
\text { Menstruação } \\
(\boldsymbol{\mu g} / \mathbf{2 4 h})\end{array}$ & $\begin{array}{c}\text { Excreção feminina } \\
\text { Gravidez } \\
(\boldsymbol{\mu g} / \mathbf{2 4 h})\end{array}$ & $\begin{array}{c}\text { Excreção feminina } \\
\text { Menopausa } \\
(\boldsymbol{\mu g} / \mathbf{2 4 h})\end{array}$ \\
\hline $\mathbf{1 7 \beta}$-Estradiol & 1,6 & 3,5 & 259 & 2,3 \\
\hline Estrona & 3,9 & 8,0 & 600 & 4,0 \\
\hline Estriol & 1,5 & 4,8 & 6,000 & 1,0 \\
\hline
\end{tabular}

Fonte: Reis Filho et al. (2006).

Mesmo que boa parte desses hormônios sejam biologicamente degradados na natureza, quantidades significativas acabam não sendo totalmente removidos nas estações de tratamento de esgoto (ETEs), e são posteriormente despejadas em águas superficiais, podendo ser encontrados em concentrações na ordem de nanogramas por litro, não obstante, os estudos vem mostrando que mesmo com o processamento nas estações de tratamento de águas, ainda não se possuem métodos que sejam totalmente eficazes na remoção desses contaminantes, até então ignorados (REIS FILHO et al., 2006). São muitas as atividades que cooperam para o aporte de CE no ambiente, sendo o esgoto bruto e os seus efluentes de unidades de tratamentos, as principais vias de deposição dos contaminantes emergentes nos recursos hídricos. A figura 2 mostra algumas vias de transporte de estrogênios no ambiente.

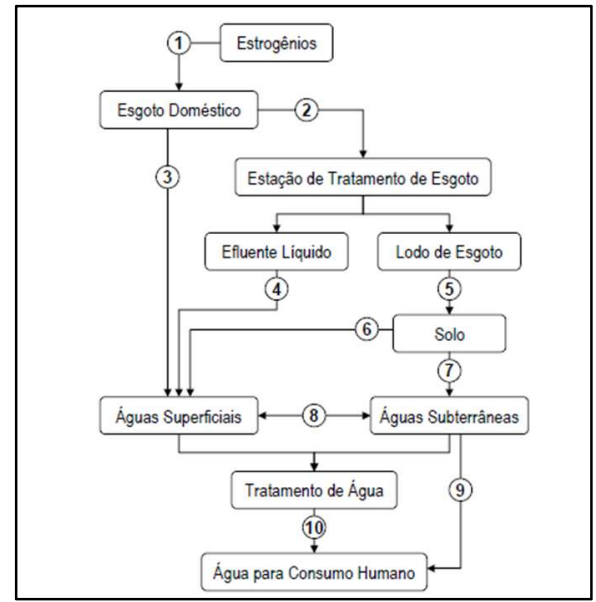

Figura 2: Aporte de Estrogênio no ambiente. Fonte: Bila et al. (2003).

A concentração desses hormônios na água final para consumo, irá depender do tratamento feito pelas estações. Sendo que sem métodos específicos e regulamentação no que diz respeito aos CE torna o problema de difícil solução. Pesquisas na quantificação desses CE são de suma importância para que se avalie a qualidade de água, e até mesmo para que sejam criados, validados e empregados métodos que viabilizem a remoção desses poluentes. Como pode ser observado na figura 2, o destino desses contaminantes podem comprometer toda uma cadeia ambiental que vai desde a vida aquática, até o homem como último da cadeia. 
As ferramentas para análises de contaminantes emergentes nos mananciais pelo mundo se aprimoram muito nos últimos anos, vários métodos foram validados, concentrações em quantidades mínimas passaram a ser detectadas e diversos estudos passaram a mostrar os potenciais tóxicos dessas substâncias no ambiente. No entanto, as substâncias pouco foram regulamentadas (RAIMUNDO, 2011).

Em 2011 foi aprovado pela USEPA um projeto de lei que monitorasse os contaminantes que não possuem regulamentação. Esse documento listava 30 contaminantes como prioridade, dentre esses contaminantes estão a estrona, o $17 \beta$ estradiol e o $17 \alpha$-etinilestradiol e o hormônio testosterona (USEPA, 2011).

A preocupação a respeito da presença dos CE nas águas que são distribuídas a população tem desencadeado uma série de debates e discussões em todo o mundo. A ineficiência de dados ecotoxicológicos e critérios de potabilização da água, sugere que haja maior intensificação de ações, a fim de prevenir a contaminação dos recursos hídricos por compostos potencialmente perigosos.

\section{Possíveis efeitos ao ambiente e ao homem}

Quando falamos em poluição ambiental, temos que ir muito além de pensar no despejo de lixo em locais inadequados, ou mesmo na conduta de descarte da população. Poluição ambiental está relacionado a uma gama de aspectos, que variam desde a contaminação do ar, das águas e do solo, desfiguração da paisagem, erosão de monumentos e construções até a contaminação da carne de aves com hormônio ou da contaminação da vida aquática por efluentes de esgotos despejados nos rios (FELLENBERG, 2013)

Segundo Matos (2010), para caracterizar situações em que a atividade humana tenha alterado o meio ambiente, uma distinção entre contaminação e poluição ambiental tem sido proposta. A contaminação tem sido utilizada para caracterizar uma situação em que determinada substância está presente no meio ambiente, mas não causa qualquer dano que seja óbvio, enquanto a poluição tem sido utilizada para situações onde os efeitos deletérios ao ambiente são potencialmente aparentes.

A poluição acontece quando há introdução de substâncias artificiais e estranhas a um meio, introdução de substâncias naturais estranhas a um determinado ecossistema ou quando há alteração nas características dos elementos que compõe o próprio meio ambiente, seja em proporção ou de constituintes. Quando a vegetação, a fauna e solo, são perdidos, removidos ou expulsos e a qualidade de água é alterada, podemos observar o que chamamos de degradação ambiental. Essa degradação ambiental é resultante de atividades que direta ou indiretamente: prejudiquem de forma negativa a biota, criem condições que prejudiquem as atividades sociais e econômicas, tragam riscos à saúde, segurança e causem desequilíbrio no bem-estar da população (MATOS, 2010).

Diante dessas colocações fica evidente a problemática dos poluentes emergentes. Desde o início do século $\mathrm{XX}$, existem estudos que vem alertando quanto à exposição de substâncias químicas tóxicas, esses $\mathrm{CE}$ se mostram potencias a causar alterações no funcionamento biológico de seres vivos como: anomalias genéticas; interferência no sistema endócrino de seres humanos e outras espécies animais. O que pode estar relacionado ao aumento no índice de neoplasias de testículo, de mama e próstata nos seres humanos; 
alterações nos órgãos reprodutivos, feminilização de peixes machos, interferências na tireoide, no sistema neurológico, diminuição da fertilidade em animais, dentre outros efeitos observados em algumas espécies (BILA et al., 2007).

Esta ameaça ao meio ambiente e a saúde humana foi colada em pauta pela primeira vez através do livro considerado um marco neste estudo, Primavera Silenciosa, escrito em 1962 pela bióloga americana Rachel Carson, onde ela verificou o efeito negativo de um pesticida largamente utilizado na época, o DDT (Dicloro-Difenil-Tricloroetano), na reprodução de aves. O interesse de autoridades cresceu após a publicação do livro Our Stolen Future (Nosso Futuro Roubado), de Theo Colburn e associados no ano de 1996, considerado como uma continuidade do livro de Rachel Carson, a obra levou a existência de um movimento ambientalista e alertou os possíveis efeitos deletérios desses contaminantes (GHISELLI et al., 2007).

Os estrogênios estrona, $17 \beta$-estradiol e $17 \alpha$-etinilestradiol recebem uma preocupação especial e são objetos deste estudo, pois são constantemente excretados no esgoto e não são totalmente extraídos nas ETE. Dessa forma, são difundidos continuamente nos ecossistemas aquáticos e podem ser localizados nas águas superficiais, águas que são fontes de consumo posteriormente para todos da sociobiodiversidade. A maioria dos processos convencionais de tratamento de água não retiram totalmente esses poluentes silenciosos, o que torna um risco constante aos humanos e às espécies animais.

\section{CONCLUSÕES}

Por meio deste estudo podemos constatar a existência de uma tensão ambiental. O desenvolvimento da economia, o aumento populacional, a urbanização e a revolução tecnológica são seguidas por alterações no estilo de vida, nos meios produtivos e no consumo da população. Como efeito direto desses processos, ocorre o aumento progressivo na geração de resíduos sólidos, tanto em quantidade como em diversidade, especialmente nos grandes centros urbanos. Além da quantidade, os resíduos produzidos atualmente passaram a ter em sua composição elementos sintéticos e perigosos aos ecossistemas e à saúde do homem, em virtude das novas tecnologias incorporadas ao cotidiano. O que acaba por interferir significantemente no que seria o equilíbrio ambiental.

Ainda não se pode dizer com clareza os possíveis resultados da interação dos poluentes que estão surgindo e os impactos que esses vão ocasionar nos organismos vivos, mas o que podemos observar é uma significativa modificação na qualidade das nossas águas, solos e problemas na saúde do ecossistema como um todo em decorrência da absorção de diferentes substâncias as matrizes biológicas.

Os mecanismos de tratamento de água utilizados no Brasil, em geral, são precários por não atenderem os padrões e condições para fornecer alta qualidade de purificação. Os poluentes emergentes não estão incluídos em programas de monitoramento de rotinas de órgãos de meio ambiente e saúde, e tampouco estão inseridos em normativas ou legislações de controle ambiental. Esta situação é crítica, pois ainda não se sabe todos os impactos sobre o meio ambiente, especialmente a longo prazo. Sendo assim, fazse necessário o aumento de pesquisas sobre a origem, a transformação e os efeitos dessa nova geração de 
poluentes, propondo mecanismos para o tratamento da água e dos solos, com o intuito de minimizar os seus efeitos, a fim de garantir uma qualidade adequada à saúde ecológica e humana.

\section{REFERÊNCIAS}

ARAÚJO, S. A. M.. Desenvolvimento e validação de um método analítico (SPE-HPLC) para determinação de compostos emergentes em águas superficiais. Tese (Doutorado) - Universidade Federal do Ceará, Fortaleza, 2014.

BILA, D. M.; DEZOTTI, M.. Fármacos no meio ambiente. Química Nova, v.26, n.4, p.523-530, 2003.

BLEDZKA, D.; GMUREK, M.; GRYGLIK, M.; OLAK, M.; LEDAKOWICZ, S.. Phtodegradation and advanced oxidation of endocrine disruptors in aqueous solutions. Catlysis Today, n.151, p.125-130, 2010.

CAMPBELL, C. G.; BORGLIN, S. E.; GREEN, F. B.; GRAYSON, A.; WOZEI, E.; STRINGFELLOW, W. T.. Biologically directed environmental monitoring, fate, and transport of estrogenic endocrine disrupting compounds in water: A review.

Chemosphere, v.65, n.8, p.1265-1280, 2006.

CERVO, A. L.; BERVIAN, P. A.. Metodologia científica. 4 ed. São Paulo: Makron Books, 1996.

CRISTALE, J.; SILVA, F. S.; MARCHI, M. R. R.. Desenvolvimento e aplicação de método GC-MS/MS para análise simultânea de 17 HPAs em material particulado atmosférico. Eclética Química, v.33, n.4, 2008.

FELLENBERG, G.. Introdução aos problemas da poluição ambiental. São Paulo: EPU, 2013.

GHISELLI, G.; JARDIM, W. F.. Interferentes endócrinos no ambiente. Química Nova, São Paulo, v.30, n.3, 2007.

GUYTON, A. C.; HALL, J. E.. Tratado de Fisiologia Médica. 12 ed. Rio de Janeiro, Elsevier, 2011.

HAMID, H.; ESKICIOGLU, C.. Fate of estrogenic hormones in wastewater and sludge treatment: a review of properties and analytical detection techniques in sludge matrix. Water Resources, v.46, p.5813-5833, 2012.

MANZINI, E. J.. Considerações sobre a entrevista para a pesquisa social em educação especial: um estudo sobre análise de dados. In: JESUS, D. M.; BAPTISTA, C. R.; VICTOR, S. L.. Pesquisa e educação especial: mapeando produções. Vitória: UFES, 2006. p.361-386.

MATOS, A. T.. Poluição Ambiental: impactos no meio físico. Viçosa: UFV, 2010.

PETROVIC, M.; BARCELÓ, D.. Liquid chromatography-mass spectrometry in the analysis of the emerging environmental contaminants. Analytical and Bionalaytical Chemistry, v.385, p.422, 2006.

RAIMUNDO, C. C. M.. Contaminantes Emergentes em água tratada e seus mananciais: sazonalidade, remoção e atividade estrogênica. Campinas: 2011.

REIS FILHO, R. W.; ARAUJO, J. C.; VIEIRA, E. M.. Hormônios sexuais estrógenos: contaminantes bioativos. Química Nova, São Paulo, v.29, n.4, 2006.

SODRÉ, F. F.; LOCATELLI, A. F.; JARDIM, W. F.. Sistema limpo em linha para extração em fase sólida de contaminantes emergentes em águas naturais. Química Nova, v.33, n.1, p.216, 2010.

TARTARI, L. C.. Avaliação do Processo de Tratamento do Chorume de Aterro Sanitário de Novo Hamburgo. Liberato, Novo Hamburgo, v.6, n.6, p.66-74, 2005.

USEPA. United States Environmental Protection Agency. Special Report on Environmental Endocrine Disruption: An Effects Assessment and Analisys. Washington: USEPA, 1997.

A CBPC - Companhia Brasileira de Produção Científica (CNPJ: 11.221.422/0001-03) detém os direitos materiais desta publicação. Os direitos referem-se à publicação do trabalho em qualquer parte do mundo, incluindo os direitos às renovações, expansões e disseminações da contribuição, bem como outros direitos subsidiários. Todos os trabalhos publicados eletronicamente poderão posteriormente ser publicados em coletâneas impressas sob coordenação da Sustenere Publishing, da Companhia Brasileira de Produção Científica e seus parceiros autorizados. Os (as) autores (as) preservam os direitos autorais, mas não têm permissão para a publicação da contribuição em outro meio, impresso ou digital, em português ou em tradução. 